\title{
Der "zweifelnde» Thomas (Joh 20,24-29) im Spiegel seiner Rezeptionsgeschichte ${ }^{1}$
}

"Doubting Thomas ${ }^{2}$ - der "zweifelnde Thomas" - ist im Englischen die Überschrift über den berühmten Abschnitt aus dem 20. Kapitel des Johannesevangeliums und zugleich die sprichwörtliche Bezeichnung für einen, der sich verhält wie eben jener Thomas, der nur glauben kann und will, was er sehen und greifen kann, einen Skeptiker. Ähnlich sprichwörtlich ist im Deutschen die Rede vom "ungläubigen Thomas". Dies ist freilich weniger angemessen, denn tatsächlich bekennt Thomas ja nach der besagten Szene seinen Glauben mit dem höchsten und kühnsten Christusbekenntnis des ganzen Johannesevangeliums: "Mein Herr und mein Gott." Insofern ist auch vom "gläubigen" oder besser "glaubenden Thomas " $\mathrm{zu}$ sprechen. Doch scheint dieser Glaube augenscheinlich erst dadurch möglich geworden zu sein, dass Thomas den Auferstandenen gesehen und berührt hat.

Oder hat er ihn vielleicht gar nicht berührt? Brauchte er die Aufforderung Jesu gar nicht mehr zu befolgen, hatte er es womöglich nach Jesu Anrede gar nicht mehr nötig, den Finger in seine Wunden zu legen? Hier sind wir schon bei den oft übersehenen `Unbestimmtheitsstellen Berühren der Wundmale Jesu wird ja nicht erzählt, und die Frage, was Thomas tatsächlich vom Unglauben oder von der Skepsis zum Bekenntnis des Glaubens bringen konnte, bleibt der Phantasie der Leser überlassen. Doch fallen solche Subtilitäten den meisten Leserinnen und Lesern des Johannesevangeliums nicht auf. Sie konjizieren einfach die sLücken in der Erzählung und rechnen so meist damit, dass Thomas tatsächlich die `Fingerprobe` machte, dass er den Auferstandenen wirklich mit seinen Händen anfasste. Doch ist das vierte Evangelium - wie in der neueren literaturwissenschaft-

1 Hans Weder zum 65. Geburtstag in freundschaftlicher Verbundenheit gewidmet. Für die kritische Durchsicht des Manuskripts danke ich meinen Mitarbeitern Nadine Kessler und Dr. Benjamin Schliesser (Zürich) sowie Dr. Anni Hentschel (Würzburg/ Frankfurt) sehr herzlich.

2 So der Titel des Buches von G.W. Most, Doubting Thomas, Cambridge, MA/London 2005; deutsche Übers.: Der Finger in der Wunde. Die Geschichte des ungläubigen Thomas, München 2007. 
lichen Forschung immer deutlicher wurde ${ }^{3}$ - ein Werk mit einer höchst subtilen narrativen Strategie, die sich jedoch nur bei näherem Hinsehen erschliesst.

Es lohnt sich, in solchen Fällen auf die Darstellungen der bildenden Künstler zu achten. Diese erweisen sich - allein durch die Aufgabe, das Erzählte ins Bild zu setzen, oft als besonders genaue Leser der biblischen Texte, auch wenn sie in vielem von ikonographischen Traditionen oder auch von den theologischen Auffassungen ihrer Zeit bzw. ihrer Auftraggeber abhängig sind. Daher möchte ich im Folgenden erst eine kunsthistorische Annäherung an die Thomasepisode versuchen, dann nach dem biblischen Thomasbild und seiner frühkirchlichen Weiterführung und weiter nach der Deutung und Rezeption der johanneischen Thomasepisode in der kirchlichen Auslegungsgeschichte fragen, bevor am Ende noch einmal nach dem Sinn und der Tragweite des "Thomaszweifels" und seiner Überwindung in Joh 20,24-29 gefragt werden kann.

\section{Thomas zwischen Caravaggio und Rembrandt}

Im Motiv des sog. >Thomaszweifels`, der bei weitem häufigsten Szene in den bildhaften Darstellungen des Thomas, ${ }^{4}$ finden sich unterschiedliche Darstellungstypen. ${ }^{5}$ Prinzipiell von der Aktion Christi aus konzipiert, ergibt sich ein Typus, in dem Christus seine Hand hebt (wobei in Verbindung damit auch die Berührung der Seitenwunde durch Thomas dargestellt werden kann), ein zweiter Typus, in dem Christus die Seitenwunde freigibt und Thomas dadurch auf sie hinweist, und ein dritter, in dem Christus selbst den Finger oder gar die Hand des Thomas zu seiner Seitenwunde führt. Die allermeisten Darstellungen lassen keinen Zweifel daran, dass es zur Berührung der Wunden Jesu kommt, auch wenn diese selbst nicht gezeigt wird. Nur wenige ältere Darstellungen bilden hier eine Ausnahme - und diese verdienen Beachtung.

\footnotetext{
3 Ein nach wie vor grundlegendes Werk dazu ist R.A Culpepper, Anatomy of the Fourth Gospel. A Study in Literary Design, Philadelphia 1983; unter den neueren Kommentaren s. insbes. H. Thyen, Das Johannesevangelium, HNT 6, Tübingen 2005 ${ }_{4}$ M. Lechner, Art. Thomas (Apostel), Lexikon der christlichen Ikonographie 8, Freiburg etc. 1976, 468-475, hier 472f.

5 S. dazu [Red.], Art. Thomaszweifel, Lexikon der christlichen Ikonographie 4, Freiburg etc. 1972, 301-303; ausführlicher Most, Der Finger in der Wunde, 201-257, mit einer eingehenden Diskussion des Bildes von Caravaggio (208ff.).
} 
Für die Darstellung des >Thomaszweifels` besonders einflussreich war die in Sanssouci bei Potsdam aufbewahrte, wohl 1601/02 entstandene Darstellung des italienischen Barockmalers Caravaggio (1571-1610), die dem dritten Typus zugehört. In einer drastischrealistischen, dem Betrachter grösstmögliche Nähe vermittelnden Darstellung, führt Jesus die Hand des zweifelnden Jüngers zu seiner Seitenwunde, und der Finger des Thomas dringt tief in die klaffende Seitenwunde Jesu ein. Es ist geradezu eine »inquisitorische Handgreiflichkeit«, die in ihrer Derbheit, ja Brutalität schockierend wirkt. ${ }^{6}$ Thomas schaut mit angespanntem Blick und weit aufgerissenen Augen in die Wunde, seine Stirn ist in tiefe Falten gelegt auch das ein Ausdruck tiefen Erschreckens über die so unerwartete Erfüllung seines Begehrens. ${ }^{7}$ Auch die beiden anderen Jünger, die hier (in künstlerischer Reduktion der Szene) mit zugegen sind, schauen Thomas interessiert und intensiv beteiligt über die Schulter. Offenbar sind auch sie keineswegs über das Ansinnen erhaben, dass die Wirklichkeit der Auferstehung und näherhin die Körperlichkeit des Auferstandenen eine so handgreifliche Verifikation erforderte.

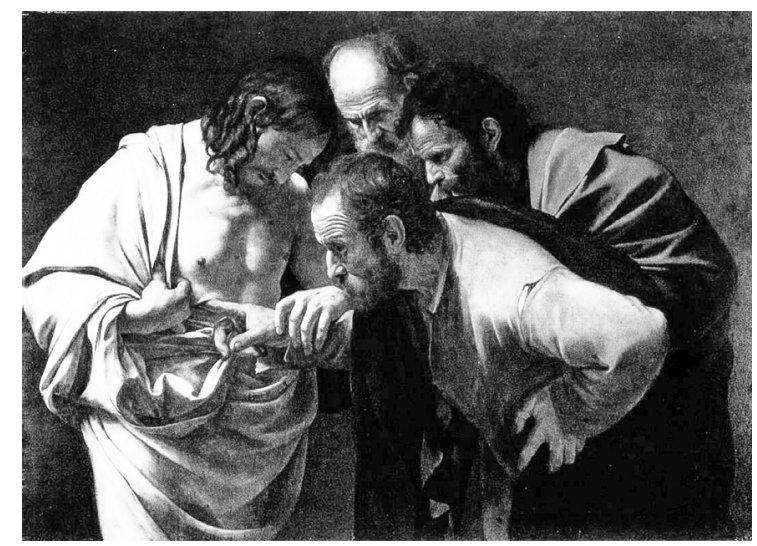

Caravaggio. Der ungläubige Thomas

\footnotetext{
6 So Most, Der Finger in der Wunde, 211, der mit Recht auf die sexuellen Konnotationen der Darstellung hinweist.

7 Zu Caravaggio und seiner Darstellung s. ebd., 207f.233-248.
} 
Jörg Frey

Caravaggios Bild hat Schule gemacht. Ein eindrücklicher `Nachfolger` dieser Darstellungsweise ist das Gemälde des kurfürstlich-bayerischen Hofmalers Ulrich Loth (1599-1662) in den Beständen der Alten Pinakothek in München. ${ }^{8}$ Auch hier führt Christus die Hand des Jüngers zu seiner Seitenwunde. Nun ist es in nochmals gesteigerter Weise die ganze Handspitze mit vier Fingern, mit denen Thomas in die Wunde und damit den Leib Jesu eindringt. Die Derbheit der Darstellung Caravaggios ist jedoch gewichen, Thomas erscheint hier fast wie ein frühmoderner Arzt, der mit konzentriertem Blick und geradezu >wissenschaftlichem Wunde Jesu inspiziert. Zugleich ist - bei Loth wie bei Caravaggio beachtenswert, dass Thomas in seinem Interesse an möglichst sorgfältiger Verifikation nicht allein ist. Die anderen Jünger, die in der Szene zugegen sind - bei Loth alle zehn -, schauen fast alle gleichfalls interessiert auf Jesu Wunde. Thomas ist also keineswegs von den anderen geschieden, als der `Noch-Ungläubige` im Gegensatz $\mathrm{zu}$ denen, die vor ihm geglaubt hatten. Das Begehren des Thomas erscheint hingegen als ein zutiefst menschliches, das nicht negativ $\mathrm{zu}$ beurteilen oder gar als `Unglaube $\mathrm{zu}$ verdammen ist, zumal ihm die Autopsie ja von Christus ausdrücklich gewährt ist. Der Zweifler Thomas bekommt `Gesellschaft, er inspiziert Jesu Leib auch für die anderen mit, die die Verifikation des Wunders mit frommem Blick verfolgen.

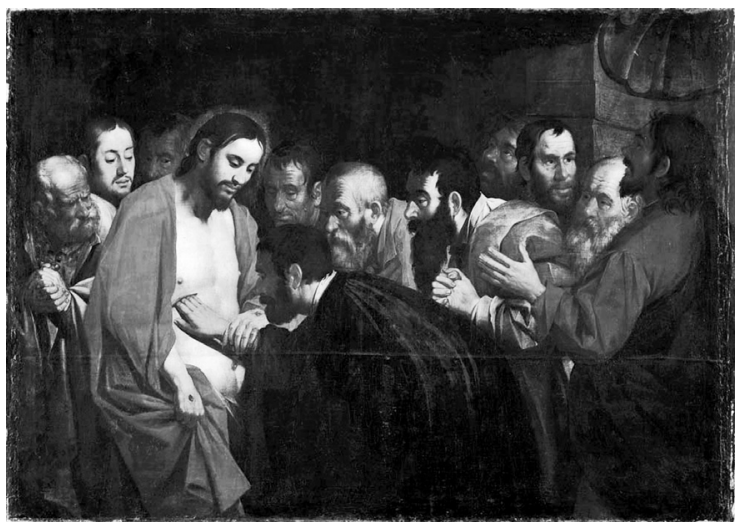

Ulrich Loth. Der ungläubige Thomas

\footnotetext{
8 S. dazu R. Baumstark u.a. (Hg.), Ulrich Loth. Zwischen Caravaggio und Rubens, Ostfildern 2008.
} 
Während die überwiegende Mehrheit der künstlerischen Darstellungen keinen Zweifel aufkommen lässt, dass es tatsächlich zur Berührung der Wundmale Jesu kommt, bieten einige wenige Kunstwerke eine alternative Sicht. Eines dieser Bilder ist ein 1613-15 entstandenes Altarbild von Peter Paul Rubens (1577-1640), das im königlichen Kunstmuseum von Antwerpen ausgestellt ist. In diesem Bild zeigt der Auferstandene Thomas lediglich seine Hand, der Oberkörper ist zwar entblösst, aber erstaunlicherweise fehlt die Seitenwunde in diesem Bild. Das traditionelle Motiv der Berührung der Seitenwunde ist damit von vorneherein ausgeschlossen. Thomas und ein anderer Jünger blicken auf das Stigma an Jesu linker Hand, ein anderer Jünger schaut auf das Gesicht oder den Mund Christi, und nichts deutet darauf hin, dass es hier zu einer Berührung der Wunde kommen sollte, die Haltung der Hände des Thomas, v.a. seiner Rechten, "scheint nicht nur Überraschung auszudrücken, sondern auch ein Zurückschaudern bei dem Gedanken, den Herrn zu berühren. " Offenbar fasst Rubens in seiner Darstellung den Moment, in dem Jesus Thomas seine Wundmale zeigt und ihn einlädt, diese $\mathrm{zu}$ betasten, oder noch reduzierter das "Sieh meine Hände! (Joh 20,27), ohne eine weitergehende Berührung ins Auge zu fassen..$^{10}$ Gerade im Kontrast zu der einflussreichen Darstellung Caravaggios ist dies bemerkenswert.

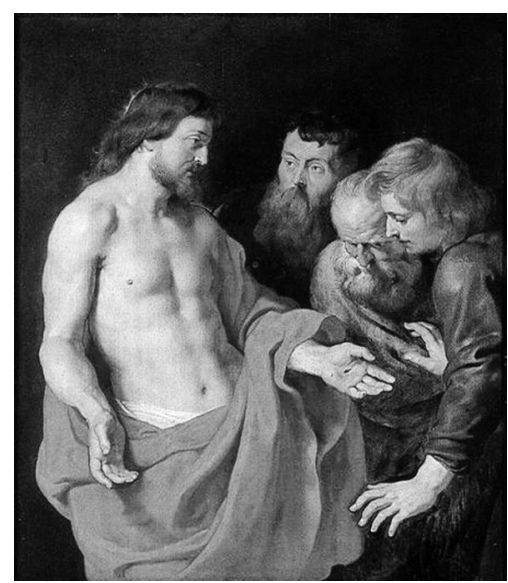

Peter Paul Rubens. Der ungläubige Thomas

9 So Most, Der Finger in der Wunde, 251.

${ }^{10}$ Most, ebd., 251, deutet das Bild so, dass Rubens die Aufforderung Jesu und den glaubenden Ausruf des Thomas verschmelzen lasse - doch letzterer bleibt m.E. im Bild nicht erkennbar. 
Jörg Frey

Eine Steigerung dieses Ausdrucks findet sich dann in einem Bild von Rembrandt (1606-1669) aus dem Jahr 1634 aus dem Moskauer Puschkin-Museum. Dieses Bild folgt dem zweiten der oben genannten Darstellungstypen: Jesus hebt lediglich sein Gewand an, entblösst seine Seitenwunde und hält sie dem zweifelnden Jünger entgegen. Nur seine eigene Hand zeigt auf die Wunde, die Hände des Thomas sind vielmehr abwehrend aufgehoben, entsetzt schreckt er zurück, und eine Berührung der Wundmale ist durch diesen Gestus völlig ausgeschlossen. Angesichts der Worte Jesu, die ihn und seine (nur gegenüber den Mitjüngern geäusserten) Gedanken sentlarven`, und angesichts der Geste des Auferstandenen, der von sich aus seine Wundmale zeigt und sich damit dem zweifelnden Jünger offenbart, kann dieser offenbar von der gewünschten handgreiflichen >Nachprüfung Abstand nehmen.

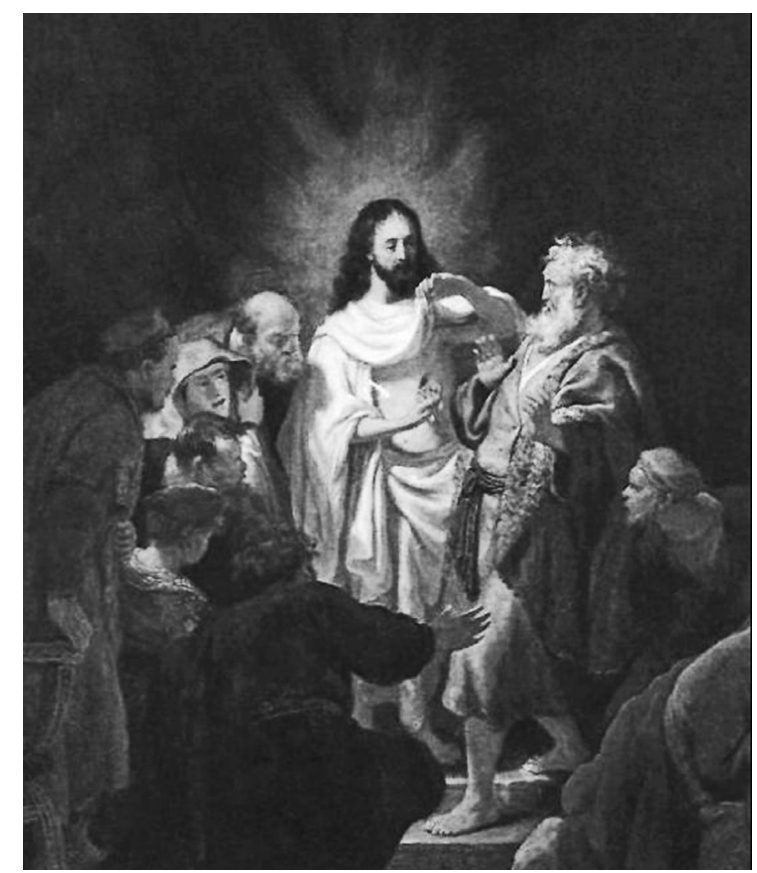

Rembrandt. Der ungläubige Thomas, Ausschnitt Szene 
Die unterschiedlichen `Lesarten $`$ der Künstler, die zugleich unterschiedliche Zugangsweisen zum Thema von Glauben und Zweifel zum Ausdruck bringen, bieten Anlass, über die Thomasgestalt und ihre Wirkungsgeschichte nachzudenken, um dann im Lichte der vielfältigen Deutungen noch einmal nach Sinn und Bedeutung dieser letzten Szene des ursprünglichen Johannesevangeliums, dem Abschluss der >Ostergeschichten in Joh 20, zu fragen..$^{11}$ Geht es hier nur um ein Problem des Thomas allein? Ist er als der `Zweifler` zu tadeln, ist sein Streben nach Verifikation ungläubig oder gar sündig? Oder ist er in seinem Ansinnen und Handeln gar ein >Modelk für andere? Und wie lässt sich der Glaube angesichts des Zweifels verstehen?

\section{Das biblische Bild des Thomas, die spätere Thomastradition und die Rezeption von Joh 20 in christlichen Apokryphen}

Wer ist Thomas? Und wie kommt er zu seinem zweifelhaften Ruf? Zunächst gehört er schlicht zum Kreis der zwölf Jünger Jesu: In allen Jüngerlisten ist er vertreten (Mt 10,3; Mk 3,18; Lk 6,15; Apg $1,13)$, jedoch völlig unprominent: ein galiläischer Jude im engsten Umkreis Jesu. Nichts ist von ihm gesagt, ausser dass er dabei war auf dem Weg Jesu und in der frühesten nachösterlichen Gemeinde.

Erst im Johannesevangelium, das zwar keinen Zwölferkreis voraussetzt, aber einzelne Jünger in Erzählszenen und Dialogen genauer fokussiert und $\mathrm{zu}$ Wort kommen lässt, bekommt Thomas eigene Konturen: Es bleibt offen, wie er zum Jüngerkreis kam, er wird (wohl in Kenntnis der synoptischen Tradition) als Mitglied dieses Kreises einfach vorausgesetzt und dann unvermittelt erwähnt. Als Jesus beabsichtigt, zu Lazarus, der schon gestorben ist, nach Bethanien zu gehen, kommentiert Thomas dieses Ansinnen: „Lasst auch uns hingehen, um mit ihm zu sterben" (Joh 11,16). In dieser Aussage spricht sich kaum heroischer Todesmut aus, sondern viel eher unverhohlene Skepsis gegenüber dem Zug Jesu in den Wirkungsbereich seiner Gegner (vgl. Joh 11,8). Der Weg mit Jesus könnte gefährlich sein. So bekundet der johanneische Thomas wie die anderen Jünger auch ein skeptisches Unverständnis für Jesu Weg; freilich erschliesst sich

${ }^{11}$ Joh 21 ist nach mehrheitlicher Auffassung der Forschung ein Nachtrag der johanneischen Redaktion, der freilich nicht weit vom Evangelium abgerückt werden darf. 
in diesem sehr charakteristischen Beispiel johanneischer $>$ Ironie ${ }^{12}$ zugleich für die Leser des Evangeliums ein tieferer Sinn: Thomas spricht in seinem skeptischen Unverständnis zugleich die Wahrheit aus, dass Jesu Gang zum Grab des Lazarus und dessen Auferweckung ihn selbst schliesslich in den Tod bringen wird (vgl. Joh 11,47-53).

Auch der zweite Auftritt des Thomas handelt von Jesu Weg: In der Abschiedsstunde stellt er Jesus eine (von Jesus selbst provozierte) Zwischenfrage (Joh 14,5): "Herr, wir wissen nicht, wohin du gehst. Wie können wir da den Weg kennen?« Das Unverständnis verwundert zumindest die johanneischen Leser, denn diese wissen ja bereits, dass Jesus >zum Vater geht (Joh 13,1f.), und die Jünger sollten dies seinen Worten (Joh 14,2-3) auch entnehmen können. Man könnte vermuten, dass Thomas hier im Besonderen als unverständig hingestellt werden sollte - evtl. im Gegensatz zu seiner Hochschätzung in anderen Kreisen - doch sind nach der johanneischen Darstellung alle Jünger vor Ostern unverständig, und das Evangelium stellt diesen Sachverhalt immer wieder heraus. Die Frage des Thomas dient in dieser durch wenige Einwürfe unterbrochenen Rede letztlich nur als 'Steilvorlage für Jesus, der sich daraufhin selbst als den wahren Weg zum Leben bzw. zum Vater (Joh 14,6) präsentieren kann. Hier erfüllt die Thomasfigur vor allem die Funktion, Jesus zu einem noch klareren Ausdruck seiner Funktion und Würde zu veranlassen. Eine weitergehende Charakterisierung seiner Person ist dieser kurzen Zwischenfrage kaum zu entnehmen.

Individuellere Konturen bekommt Thomas erst in der Ostererzählung Joh 20, wo er bei der ersten Begegnung des Auferstandenen mit den Jüngern am Ostertag - aus unbekannten Gründen - nicht zugegen ist (Joh 20,24). Während die anderen in dieser Begegnung - als Jesus ihnen seine Hände und seine Seite zeigt und sie mit dem Friedensgruss anredet - "sich freuen" und damit zum Glauben an ihn als den Auferstandenen gelangen (Joh 20,20), kann Thomas auf den blossen Bericht der anderen hin noch nicht glauben. Ihnen und nur ihnen - gegenüber äussert er seinen Zweifel bzw. seinen Wunsch nach einer >Autopsie, ja einer handgreiflichen Verifikation des Glaubens (Joh 20,25). Bei der nächsten Zusammenkunft, die

\footnotetext{
${ }^{12}$ Dieses Stilmittel der sironischen hannesevangelium, das seinen Leserinnen und Lesern die Fähigkeit abverlangt, die verschiedenen Ebenen der Aussage zu unterscheiden - zu erkennen. Thomas als erzählerische Figur - Erzählfigur wird durch diese Aussage als skeptisch und unverständig für Jesu Weg charakterisiert (vgl. auch Joh 14,5), während der Text seinen Lesern damit zugleich eine tiefere christologisch-soteriologische Einsicht nahebringt, die natürlich für die innertextliche Figur des Thomas noch nicht vorausgesetzt werden kann (und noch viel weniger für einen historischen Jünger des irdischen Jesus),
} 
nach Johannes auffälligerweise acht Tage später erfolgt, ${ }^{13}$ tritt ihm Jesus von sich aus entgegen, bietet ihm eine solche handgreifliche Verifikation an und erweist sich gerade dadurch bereits als derjenige, der um die verborgenen Zweifel und Bedürfnisse seines Jüngers weiss. Das letzte Element der Worte Jesu, die Aufforderung "nicht ungläubig, sondern gläubig" zu sein (Joh 20,27), impliziert eine Charakterisierung der bis dahin vorherrschenden Haltung

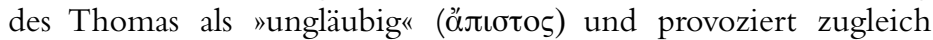
das Glaubensbekenntnis des Thomas, das sachlich das höchste Christusbekenntnis des Johannesevangeliums überhaupt ist: „Mein Herr und mein Gott!« Die Antwort Jesu: »Du glaubst, weil du mich gesehen hast. Selig, die nicht mehr sehen und glauben! ${ }^{14}$ lässt fragen, ob und inwiefern darin ein Tadel an Thomas und seinem Insistieren auf dem Sehen (und darüber hinaus gar auf der Fingerprobe) liegen soll. Sicher aber enthält sie eine Verheissung an andere (wohl später) Glaubende, d.h. primär an die Leserinnen und Leser des Evangeliums, die in einer späteren Zeit nicht mehr wie Thomas mit eigenen physischen Augen sehen können und dennoch zum Glauben kommen können und sollen. Mit dieser letzten Anrede Jesu an Thomas endet das Thomasbild des ursprünglichen Evangeliums. Im Nachtragskapitel Joh 21, in dem dann - anders als im bisherigen Text des Evangeliums - eine Jüngerliste aufgenommen ist, die nicht zwölf, sondern (nur) sieben Namen enthält, begegnet Thomas relativ prominent nach Petrus an zweiter Stelle (Joh 21,2), was sicher auch seine durch Joh 20 gewonnene Bedeutung reflektiert, doch wird sonst in diesem Kapitel nichts weiter von ihm berichtet.

Bieten die Daten Anhaltspunkte für eine weitergehende Charakterisierung der Figur des Thomas? Abgesehen von der Szene in Joh 20 bleiben die Indizien m.E. dürftig, und sie erlauben kaum, Thomas in besonderer Weise den Charakter eines 'Skeptikers` zuzuschreiben. ${ }^{15}$ >Unverständig` sind im vierten Evangelium alle Jünger des irdischen Jesus, mit Ausnahme des idealen 'Lieblingsjüngers،. Präzisere Anhaltspunkte, um die in Joh 20,25 geäusserte Skepsis psychologisierend aus dem bereits bekannten Charakterbild des

${ }^{13}$ Es ist anzunehmen, dass in der Zeit und im Umfeld der Abfassung des Johannesevangeliums bereits eine sonntägliche Zusammenkunft der Gemeinde vorausgesetzt ist.

${ }^{14}$ So die neue Zürcher Übersetzung, die anders als die Lutherübersetzung »die nicht sehen und doch glauben " keinen Gegensatz von Glauben und Sehen impliziert und die Seliggepriesenen exegetisch m.E. zu Recht auf die Glaubenden der späteren Zeit bezieht. Letztlich sind hier wohl die Adressaten des Evangeliums angesprochen.

${ }^{15}$ So aber bei E. Käsemann, Jesu letzter Wille nach Johannes 17 , Tübingen ${ }^{4} 1980$, $158 \mathrm{fff}$. 
Thomas (d.h. aus den beiden vorherigen Erwähnungen) zu erklären oder um zu verstehen, ${ }^{16}$ warum gerade für ihn eine so drastische >Demonstration` der Wirklichkeit der Auferstehung notwendig wäre, gibt das Evangelium nicht.

An diesem biblischen Thomas-Bild wird nun in verschiedenen Traditionen des frühen Christentums intensiv 'weitergearbeitet<, wozu wohl vor allem die Lückenhaftigkeit dieses Bildes Anlass gibt. Die Fragen, wer dieser Thomas wirklich war, wie er zu Jesus stand und was er später tat, bewegten die Gemüter. Dabei gibt es zwei Hauptlinien: die durch eine Reihe von Thomas zugeschriebenen Schriften charakterisierte >Thomastradition`, in der Thomas als besonderer Offenbarungsempfänger geschätzt wird, und die an Joh 20 anknüpfende Weiterdeutung der Thomasgestalt, die sich mit dem Zweifel des Thomas auseinanderzusetzen hat bzw. natürlich eher an die Thomas zuteil gewordene Glaubensvergewisserung anknüpft. ${ }^{17}$

Anknüpfungspunkt für die Thomastradition ${ }^{18}$ ist der Name. Dieser wird in Joh 11,16;20,24 und 21,2 ins Griechische übersetzt:

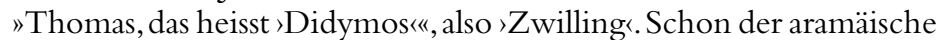
Name $\mathrm{T}^{\mathrm{e}}$ 'ômāh bedeutet `Zwilling , dies wird nun übersetzt und so entsteht später ein redundanter Quasi-Doppelname »Didymus

\footnotetext{
${ }^{16}$ Die These von J.H. Charlesworth, dass der johanneische Lieblingsjünger mit Thomas zu identifizieren sei, so dass er es gewesen wäre, der die Kreuzigung gesehen hätte (J.H. Charlesworth, The Beloved Disciple. Whose Witness Validates the Gospel of John?, Valley Forge, PA $\left.{ }^{1} 1995\right)$, braucht hier nicht diskutiert zu werden. Die Gründe, die für diese Identifikation sprechen, sind nicht überzeugend.

${ }^{17}$ Diskutiert wird natürlich auch das Verhältnis zwischen der Thomastradition, die man dann v.a. in oder hinter dem Thomasevangelium zu sehen hat, und dem Johannesevangelium. Das Verhältnis kann hier nicht eingehend diskutiert werden. Die gelegentlich vorgetragene Annahme, dass bereits das Johannesevangelium auf eine ältere, theologisch andersartige und mit Thomas verbundene Tradition kritisch reagiere und diese dann dogmatisch korrigieren wolle und deshalb Thomas in einem negativen Licht als Zweifler darstelle (so z.B. U.B. Müller, Die Menschwerdung des Gottessohnes. Frühchristliche Inkarnationsvorstellungen und die Anfänge des Doketismus, Stuttgarter Bibelstudien 140, Stuttgart 1990, 36ff., und zuletzt J. Hartenstein, Charakterisierung im Dialog. Maria Magdalena, Petrus, Thomas und die Mutter Jesu im Johannesevangelium im Kontext anderer frühchristlicher Darstellungen, Göttingen 2007, 262ff., kann m.E. nicht hinreichend begründet werden; insbesondere bleibt die vorausgesetzte frühe Datierung der Thomasüberlieferung unsicher.

18 Zur späteren Thomasliteratur zählen üblicherweise neben dem Thomasevangelium, belegt in 3 Papyri aus Oxyrhynchos (POxy 1, 654, 655) und einem späteren koptischen Text aus Nag Hammadi (NHC II/2), das Buch von Thomas dem Athleten (NHC II/7), die Thomasakten, das sog. Kindheitsevangelium des Thomas und die Thomasapokalypse. Dazu vgl. M. Janssen, Evangelium des Zwillings? Das Thomasevangelium als Thomas-Schrift, in: J. Frey u.a. (Hg.), Das Thomasevangelium. Entstehung - Rezeption - Theologie, BZNW 157, Berlin/New York 2008, 222-248.
} 
Thomas«. Thomas war dabei kaum sein tatsächlicher Name, denn vorchristlich ist dieser Name nicht gebräuchlich. ${ }^{19}$ Eher ist wohl an einen Beinamen zu denken, unter dem dieser Mann bekannt war, vermutlich einfach, weil er einen Zwillingsbruder hatte und insofern selbst auch Zwillingsbruder war. Die Frage ist dann nur: Wer war dieser Zwillingsbruder des Thomas? Er bleibt ungenannt, vermutlich war er völlig unbedeutend und gehörte nicht zum Jüngerkreis Jesu. Doch knüpft die Thomastradition eben an diese 'Lücker an und identifiziert Thomas nicht nur mit dem Jünger, der in Joh 14 als nächster eine ‘Zwischenfrage` stellt, dem sonst unbekannten randeren Judas« (Joh 14,22: "Judas, nicht der Iskariot«), sondern identifiziert diesen anderen Judas zugleich mit dem in Mk 6,3 als Bruder Jesu erwähnten Judas, von dem nach Jud 1 auch der Judasbrief verfasst sein will. So avanciert Thomas zum leiblichen Bruder, genauer zum Zwillingsbruder Jesu ${ }^{20}$, und das heisst: $z u$ dessen Intimus, dem besonderes Wissen um seinen Zwillingsbruder zukommt oder besondere Offenbarung zuteil wurde, oder zu Jesu `Double`, der an der Stelle seines Zwillingsbruders redet und handelt und mit diesem sogar gelegentlich verwechselbar ist.

Die Gleichsetzung des Judas aus Joh 14,22 mit Thomas begegnet in syrischen Textzeugen des Johannesevangeliums und wohl auch im griechischen Fragment des Anfangs des Thomasevangeliums in POxy 654 Z. 2-3, das Thomas explizit als Traditionsträger einführt: "Dies sind die verborgenen Worte, die der lebendige Jesus sprach, und aufgeschrieben hat sie Judas, der auch Thomas heisst. ${ }^{21}$ Die noch vollere Namensform "Didymus Judas Thomas", die deutlich auf die Tradition von Thomas als Zwilling verweist, begegnet dann im späteren koptischen Text dieser Evangelieneröffnung (NHC II 32,11f.). In Logion 13 wird Thomas im Vergleich mit Petrus und Matthäus als Offenbarungsträger besonders hervorgehoben, wenn Jesus zu ihm sagt: "Ich bin nicht dein Lehrer. Denn du hast ge-

19 A.F.J. Klijn, John XIV 22 and the Name of Judas Thomas, in: Studies in John, FS J. N. Sevenster, NT.S 24, Leiden 1970, 88-96, hier 89 Anm. 3.

${ }^{20}$ Dass die biblischen Geburtsgeschichten nichts davon wissen, dass Jesus der »erste Sohn" Marias (Lk 2,7) war und keinen Zwillingsbruder besass, hat die spekulative Konstruktion offenbar nicht behindert. Es gibt andere altkirchliche Überlieferungen, in denen Thomas der Zwilling eines anderen ist, so von Eliezer (Ps.-Clem. Hom II 1,2) oder von Lysia (im Chronicon Paschale). S. dazu Janssen, Evangelium des Zwillings?, 226 Anm. 20.

${ }^{21}$ Freilich ist hier der Name des Judas nicht erhalten und nach dem Text der koptischen Übersetzung ergänzt. Vgl. H. Attridge, The Greek Fragments, in: B. Layton (Hg.), Nag Hammadi Codex II,2-7[...], Vol. 1, NHS 20, Leiden etc. 1989, 95-128, hier 113. Der Name Judas Thomas erscheint auch in der Abgarsage (Euseb h.e. I 13). 
trunken, du hast dich berauscht an der sprudelnden Quelle, die ich ausgemessen habe.« Dann sagt Jesus ihm im Verborgenen drei Worte, und auf die Nachfrage der Mitjünger sagt Thomas: „Wenn ich euch eines von den Worten sage, die er mir gesagt hat, werdet ihr Steine aufheben (und) auf mich werfen, und Feuer wird aus den Steinen herauskommen (und) euch verbrennen. ${ }^{22}$ Thomas ist nach dieser Überlieferung der Intimus Jesu, der prototypische Jünger, der mit Jesus eins, ja durch die ihm gegebene Offenbarung sogar ihm gleich geworden ist. ${ }^{23}$ Das in demselben Codex überlieferte Buch von Thomas >dem Athleten (Liber Thomae NHC II/7), ein Dialog des Auferstandenen mit Judas Thomas, der von Matthäus niedergeschrieben sein soll, nimmt die Zwillingsthematik explizit auf: »Der Erlöser sprach:

'Bruder Thomas, höre mir zu [...], damit ich dir enthülle, was $\mathrm{du}$ in deinem Herzen zu ergründen hast. Weil aber gesagt wurde, dass du mein Zwilling und mein einzig wahrer Freund bist, deshalb ergründe dich selbst und erkenne, wer du bist, wie du bist und wie du sein wirst! $\aleph^{24}$ Weil du mein Bruder genannt wirst, darfst du nicht in Unkenntnis über dich selbst bleiben. «

Als Zwillingsbruder Jesu ist Thomas über alle andern Jünger hinausgehoben, mehr als andere Dialogpartner Jesu (Maria Magdalena, Jakobus, Judas Iskariot etc.), ${ }^{25}$ die in den meist gnostischen Dialogevangelien zur Legitimation der zusätzlichen, seigentlichen Offenbarung dienen. Am weitesten ausgeführt ist die Zwillingstradition in den apokryphen Thomasakten, in denen der Apostel "Judas Thomas, der auch Zwilling heisst", in Indien missioniert und immer wieder Züge Jesu trägt: Dort hat Judas Thomas nicht nur den gleichen Beruf wie Jesus und sein Vater Josef, nämlich Zimmermann, er vollbringt auch ähnliche Wundertaten wie jener, und es werden ihm die Worte Jesu in den Mund gelegt. Selbst äusserlich wird

\footnotetext{
${ }^{22}$ Nach J. Schröter/H.-G. Bethge (Hg.), Das Evangelium nach Thomas (NHC II,2), in: Nag Hammadi Deutsch I (GCS Neue Folge 8: Koptisch-gnostische Schriften 2), Berlin/New York 2001, 151-181, hier 166.

${ }^{23}$ So Log 108: "Jesus spricht: Wer von meinem Mund trinken wird, wird werden wie ich. Ich selbst werde zu ihm werden, und was verborgen ist, wird sich ihm offenbaren« (ebd., 180)..

${ }^{24}$ Nach H.-M. Schenke, Das Buch des Thomas (NHC II,7), in: Nag Hammadi Deutsch I, 279-291, hier 285.

${ }^{25}$ Vgl. etwa Maria Magdalena im Mariaevangelium, Judas Iskariot im Judasevangelium (Codex Tchacos), ein anderer Judas (vielleicht auch Judas Thomas) im Dialog des Erlösers (NHC III/5), und der Herrenbruder Jakobus in den beiden Jakobusapokalypsen aus Nag Hammadi (NHCV/3 undV/4).
} 
Thomas `der Zwilling`seinem Bruder zum Verwechseln ähnlich:Als Jesus selbst erscheint, muss er erst klarstellen, dass er nicht sein Bruder ist (ActThom 11). Und als Thomas auf einer Eselin in die Stadt einzieht, spricht diese ihn als "Zwillingsbruder des Christus, Apostel des Höchsten und mit eingeweiht in das verborgene Wort des Christus" an (ActThom 39) ${ }^{26}$ Das Motiv des Zwillings-Verhältnisses kennzeichnet die Thomasakten durchgehend, wobei Anspielungen auf Joh 20 vorkommen, ${ }^{27}$ das Motiv des Unglaubens bzw. Zweifels aber komplett fehlt.

Hingegen findet sich eine Anknüpfung an den zweifelnden Thomas von Joh 20 in der Epistula Apostolorum, wo die Jünger berichten, dass sie den Auferstandenen erst für ein Gespenst hielten (vgl. Lk 24,37): Und wir glaubten nicht, dass er es wäre. Aber er war es." Danach wird die in Joh 20 erzählte Thomas-Episode auf andere Jünger ausgedehnt.

»Weshalb zweifelt ihr? [Und warum] seid ihr ungläubig? Ich bin es, der euch gesagt hat, in betreff meines Fleisches und meines Todes und meiner Auferstehung. Und damit ihr erkennt, dass ich es bin, so lege, Petrus, deine Hand [und deine Finger] in das Nägelmal meiner Hände und du, Thomas, in meine Seiten, und du auch, Andreas, sieh, ob mein Fuss auf die Erde tritt und dabei eine Spur hat. $\mathbb{1}^{28}$

Hier geht es also darum, dass nicht nur Thomas, sondern alle Jünger die real-leibliche Auferweckung Jesu handgreiflich zu fassen bekommen und bezeugen können, dass es sich nicht um eine Täuschung handelte. Die Erfahrung des Thomas wird insofern ausgeweitet.

Auch in dem koptischen "Buch der Auferstehung Jesu Christi, unseres Herrn « begegnen umfangreiche Thomas-Erzählungen. ${ }^{29}$ Dabei findet sich zunächst eine Erklärung seiner Abwesenheit am Ostertag: Thomas musste zum Begräbnis seines Sohnes Siophanes reisen. Sein rätselhaftes, vielleicht sogar tadelnswertes Fehlen in der

${ }^{26}$ Text nach H.J.W. Drijvers, Thomasakten, in: W. Schneemelcher (Hg.), Neutestamentliche Apokryphen II: Apostolisches, Apokalypsen und Verwandtes, Tübingen ${ }^{6} 1997,289-367$, hier 319.

${ }^{27}$ Z.B. in der Gebetsanrede "Mein Herr und mein Gott», ActThom 144 und Act Thom 167.

${ }^{28}$ EpApost 12(22), nach dem äthiopischen Text, bei C.D.G. Müller, Epistula Apostolorum, in: W. Schneemelcher (Hg.), Neutestamentliche Apokryphen I, Tübingen 51987, 205-233, hier 211.

${ }^{29}$ Text bei M. Westerhoff, Auferstehung und Jenseits im koptischen "Buch der Auferstehung Jesu Christi, unseres Herrn«, Orientalia Biblica et Christiana 11, Wiesbaden 1999, 177-193. 
Versammlung der Jünger hat mithin einen guten Grund. Am Grab des Sohnes angekommen, erweckt er diesen im Namen Christi vom Tod (c. 68), woraufhin Siophanes seinem Vater und dann der Menge von einer Jenseitsreise erzählt, die Menge zu seinem Vater Thomas führt und dieser dann 12000 Menschen tauft und Siophanes zum Bischof einsetzt (c. 69-71). Thomas kehrt auf einer Wolke zurück zu den Aposteln am Ölberg, die ihm von der zwischenzeitlichen Erscheinung Jesu erzählen (c. 73f.). Darüber wird Thomas traurig und fleht zu Jesus um die sichtbare Offenbarung als Auferstandener, bevor er zum Vater zurückkehre (c. 75). Die Apostel mahnen ihn zum Glauben, doch Jesus erscheint ihm und zeigt ihm über die in Joh 20 genannten hinaus noch weitere Wunden, verheisst ihm seine Gemeinschaft und versiegelt ihn mit dem Blut seiner Seitenwunde, um dann mit letzten Mahnworten zum Himmel zu fahren (c. 76-82). Der Zweifel des Thomas ist hier zwar noch berichtet, aber ganz abgemildert, motiviert aus der Trauer, dass er nicht dabei war, als Jesus erschien, und überlagert durch das legendarische Motiv, dass Thomas schon zuvor (!) im Namen Christi seinen Sohn auferweckt hat.

\section{Die Thomasepisode im Fokus ihrer Ausleger von der Alten Kirche bis zur Reformation}

Kommen wir von diesen apokryphen, meist narrativen Weiterdeutungen in den Bereich der Bibelauslegung, ${ }^{30}$ so fällt zunächst einmal auf, wie wenig die Thomasepisode bei den frühen antignostischen Autoren rezipiert ist. Irenäus bezieht sich in seinem ganzen Werk nicht einmal auf Joh $20,28,{ }^{31}$ und auch bei Tertullian ist Thomas auffällig selten erwähnt. Vielleicht war diese Gestalt für die Wahrnehmung dieser Autoren zu sehr von dogmatisch zweifelhaften Traditionen besetzt, als dass man sie hätte positiv aufnehmen können. Tertullian erwähnt Thomas explizit als negatives Beispiel für einen Menschen, der erst sehen, hören und tasten muss, um glauben zu können, ${ }^{32}$ im Gegensatz zu Maria Magdalena, die ihn aus Liebe

\footnotetext{
${ }^{30}$ Dazu lässt sich nun die materialreiche Untersuchung von Most, Der Finger in der Wunde, 160ff. heranziehen, auf die ich mich im Folgenden weitgehend stütze.

${ }^{31}$ B. Mutschler, Das Corpus Johanneum bei Irenäus von Lyon, WUNT 189, Tübingen 2006, 31. Mehrfach verweist Irenäus darauf, dass Jesus den Jüngern die Nägelmale und die Seitenwunde zeigte (V 7,1; V 31,2), doch nimmt er nicht auf Thomas Bezug.

${ }^{32}$ Tertullian, De anima 50,5 (CCL 2. 856).
} 
zu berühren versuchte. ${ }^{33}$ Wenn die Thomas-Szene erwähnt wird, dann vor allem als Beleg dafür, dass die Sinneswahrnehmung der Zeugen Jesu zuverlässig war ${ }^{34}$ und dass Jesus durch die Aufforderung an Thomas, seine Seite zu berühren, die zweifelnden Jünger davon überzeugen wollte, dass er als derselbe, der er vor seinem Tod war, auferstanden war. ${ }^{35}$ Die Thomasepisode wird also von Anfang an - und später fast ausschliesslich - als >Beweis` der tatsächlichen, leiblichen Auferweckung Jesu gewertet. Die Gestalt des Thomas und sein Zweifel hat in dieser dogmatischen Beweisführung nur ganz nachrangige Bedeutung. Dass in diesem argumentativen Kontext in der Regel mit einer tatsächlichen Berührung des Auferstandenen gerechnet wird, ist klar. Freilich zitiert Tertullian zum Beweis der physischen Realität der Auferstehung Jesu dann doch den eindeutigen rantidoketischen Bericht aus Lukas 24, in dem die Vorstellung, der Erscheinende sei ein blosser >Geist‘, ausdrücklich abgewiesen wird (Lk 24,39). ${ }^{36}$ Insofern bleibt es erstaunlich, wie spärlich die Thomasepisode bei diesen frühen Autoren aufgenommen ist, ${ }^{37} \mathrm{ob}-$ wohl sie eine herausragende Argumentationshilfe im Kampf gegen die gnostischen Auffassungen geboten hätte. Aber vielleicht war Thomas diesen Autoren aufgrund seiner Prominenz in gnostischen Kreisen doch zu suspekt, als dass man sich breiter auf sein Zeugnis hätte beziehen können.

Ein positiveres Bild des Thomas findet sich interessanterweise bei Origenes. Hier ist Thomas nicht der Ungläubige und Skeptiker, sondern vielmehr ein Mensch, der »mit Sorgfalt und Bedacht zu urteilen pflegt und [...] auf den Bericht der anderen Jünger nicht misstrauisch reagiert, sondern lediglich mit äusserster Vorsicht das Risiko auszuschliessen versucht, dass man hier einem blossen Phantasma aufsitzt. $\aleph^{38}$ Eben dies war nämlich der Einwand, den der mittelplatonische Christentumskritiker Kelsos, der erste grosse heidnische Leser der Evangelien, geäussert hatte: Nach seinem Tod habe Jesus ein Bild ( $\varphi \alpha v \tau \alpha \sigma i \alpha v)$ seiner Wunden ausgesandt, obwohl er in Wahrheit ohne diese Wunden existierte. ${ }^{39}$ Allerdings ist das Verständnis des Origenes deutlich subtiler und nicht allein an der 'Materialität des Auferstandenen interessiert: Origenes bedenkt,

33 Tertullian, Adv Praxean 25,2 (CCL 2, 1195f.).

${ }^{34}$ So bei Tertullian, De anima 17,1 (CCL 2, 806).

${ }^{35}$ So bei Hippolyt, De resurrectione, frg. 7 (GCS 9,1, 253).

36 Tertullian, De carne Christi 5,9 (CCL 2, 882).

37 So Most, Der Finger in der Wunde, $172 \mathrm{f}$.

38 So ebd., 179 unter Bezug auf Origenes, Katenenfragmente 106 (GCS 11,4, 561).

${ }^{39}$ Celsus II 61 (183,17-19 Koetschau), s. dazu J.G. Cook, The Interpretation of the

New Testament in Greco-Roman Paganism, STAC 3, Tübingen 2000, 56. 
dass der Auferstandene seine Nägelmale zeigte, aber auch durch geschlossene Türen ging, so dass nach seinem Urteil Jesus bei seiner Auferstehung "sozusagen die Mitte einhielt zwischen dem festen Leibe, den er vor seinem Leidensweg hatte, und dem Zustand, in dem die Seele frei von einem solchen Leibe erscheint. ${ }^{40}$ Nach Origenes war also »die Kontinuität des Leibes Jesu über Tod und Auferstehung hinweg nicht durch dessen Materialität gewährleistet [...], sondern

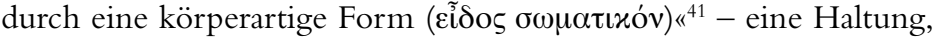
die ihn selbst schliesslich dem Häresieverdacht aussetzte. Später wurde - auch gegenüber Origenes selbst die Thomasepisode ausschliesslich zum Beweis der Materialität des Auferstandenen angeführt, ${ }^{42}$ und die Auffassung, dass Thomas tatsächlich die Wunden Jesu berührt habe, wurde zum festen Bestand der christlichen Orthodoxie der Spätantike und des Mittelalters.

Nur bei vier grossen Auslegern dieses Zeitraums, bei Augustinus, Euthymios Zigabenos, Albertus Magnus und Thomas von Aquin blitzt kurz die Überlegung auf, ob Thomas Jesu Leib wirklich berührt haben könne, und stets wird diese Überlegung schnell wieder fallen gelassen. ${ }^{43}$ So nimmt Augustinus zwar wahr, dass Joh 20,29 nur formuliert: "Weil du mich gesehen hast, glaubst du", und dass von einem tatsächlichen Betasten nichts gesagt ist, aber der Gedanke, dass der Jünger nicht hinzufassen wagte, wird dann schnell wieder weggeschoben mit dem Argument, dass der Gesichtssinn hier im Sinne einer synekdoche für jede Art von Sinneswahrnehmung stehen könne. ${ }^{44}$ Und nach dem konstantinopolitanischen Mönch Euthymios (12. Jh.) glaubte Thomas, als er die Nägelmale und Jesu durchbohrte Seite sah "auf der Stelle und musste ihn nicht erst berühren«, doch fügt er sogleich hinzu, dass sandere sagten, "nachdem er ihn berührt habe, habe er aufgeschrien: >Mein Herr und mein Gott! « ${ }^{45}$ Albertus Magnus verweist auf die zweifelnde Äusserung Augustins und erwähnt, dass manche meinten, Thomas habe aus Ehrfurcht nicht gewagt, Jesus zu berühren, freilich hält er den Glauben, dass Jesus den Herrn berührt habe, für frömmer und insofern vorzuziehen, ${ }^{46}$ und auch der Aquinate zieht sich letztlich auf die Antwort Augustins

\footnotetext{
${ }^{40}$ So Origenes Celsus II 62.

${ }^{41}$ Most, Der Finger in der Wunde, 180.

42 So z.B. bei Methodius von Olympos, De Resurrectione I 26,1 (GCS 27, 253); III

12,5-7 (GCS 27, 408f.); weitere Belege bei ebd., $181 \mathrm{f}$.

${ }^{43}$ S. die Diskussion ebd., 182-185.

${ }^{44}$ Augustinus Tract in Ioh. 121,5 (CCL 36,667).

45 Euthymios Zig., PG 129,1489A; dt. nach Most, Der Finger in der Wunde, 183.

${ }^{46}$ Super Johannem, cap 20,28-31 (Alberti Magni opera omnia, ed. Auguste Borgnet, Bd. 24, Paris 1899, 695); zit. bei Most, Der Finger in der Wunde, 184.
} 
zurück, dass das Sehen in V. 29 stellvertretend auch für andere Sinneswahrnehmungen, d.h. das Betasten stehen könne. ${ }^{47}$ An der tatsächlichen Berührung haben auch die grössten Johannesausleger des Mittelalters nicht zu zweifeln gewagt.

Welche Rolle spielt in diesen Auslegungen die Figur des Thomas und sein Zweifel? Gewiss begegnen gelegentlich tadelnde Bemerkungen darüber, dass Thomas erst glauben wollte, nachdem er gesehen hatte, ja dass er den Leib des Auferstandenen "mit neugierigen Händen" betastet habe. ${ }^{48}$ Doch ganz überwiegend wird die Episode als ein für den Glauben nützliches Geschehen gedeutet, ${ }^{49}$ durch das die Lehre von der Auferstehung Jesu noch klarer und nachdrücklicher bekräftigt werden konnte, ${ }^{50}$ da nun »die augenscheinlichste Wirklichkeit seines wieder lebendig gewordenen Fleisches ihren Augen und Händen nicht bloss zum Sehen, sondern auch zum Berühren und Betasten dargeboten war. $\aleph^{51}$ Häufig wird das Betasten des Thomas mit dem rapostolischen Plurak "was unsere Hände betastet haben" (1 Joh 1,1) in Verbindung gebracht, ${ }^{52}$ so dass Thomas nun repräsentativ für das gesamte apostolische Zeugnis dessen Wahrheit bezeugt. Sogar seine Abwesenheit bei der ersten Erscheinung Jesu im Jüngerkreis kann als eine göttliche Fügung betrachtet werden, denn "die Ungläubigkeit des Thomas hat uns

\footnotetext{
${ }^{47}$ Evangelium secundum Joannem, cap. 20, lectio 6,4 = S. Thomae Aquinatis in evangelis S. Matthaei et S. Joannis commentaria, editio IV Taurinensis II, 502); s. dazu Most, Der Finger in der Wunde, 184f.

${ }^{48}$ So Augustin, Tract in Ioh 66,2; in Tract in Ioh 16,4 verweist Augustin darauf, dass Jesus Thomas ähnlich wie den königlichen Beamten in Joh 4,48 tadelt.

${ }^{49}$ So z.B. Leo der Grosse in einer Predigt (Sermo XXXIV,4, aus: Th. Steger, BKV 54, München 1927, 163): "Wie es für uns alle von Nutzen war, dass nach der Auferstehung des Herrn die Hand des Apostels Thomas die Wundmale des Leibes Christi untersuchte».

${ }^{50}$ So etwa nach den Auslegungen von Johannes Chrysostomus (PG 59,681f.) und Gregor d. Grossen (Homilie 26 = PL 76,1201C), angeführt bei Most, Der Finger in der Wunde, $185 \mathrm{f}$.

${ }^{51}$ So Augustin, Tract in Ioh 122,6 (Übers. nach Th. Specht, BKV 19, München 1914).

52 So z.B. bei Ambrosius, Comm in Luc V,8 (aus: J.E. Niederhuker, BKV 21, München 1915, 96): »Aber auch wir [Heiden] haben in Johannes gesehen, mit unseren Augen in den Aposteln geschaut, mit unseren Händen mit des Thomas Fingern prüfend getastet; denn svon Anfang war, was wir gehört und was wir gesehen, mit unseren Augen geschaut und unseren Händen prüfend getastet haben«". Auch Cyrill v. Alex, De incarnatione unigeniti 2.
} 
nämlich für den Glauben mehr Nutzen gebracht als der Glaube der gläubigen Jünger «. ${ }^{53}$

Insgesamt ist aber festzustellen, dass die Figur des Thomas und sein Zweifel in der altkirchlichen und mittelalterlichen Auslegung deutlich zurücktritt hinter den mit diesem Text verbundenen dogmatischen Interessen. Im Fokus ist nicht der individuelle Jünger, erst recht nicht die literarische Gestalt des johanneischen Textes, sondern das dahinter als historisch angenommene Geschehen, die daraus $\mathrm{zu}$ entnehmende Lehre (über die leibliche Auferstehung, die Beschaffenheit des Leibes Jesu oder die zwei Naturen Christi). Dabei wird der explizierte Unglaube des Thomas gerne heruntergespielt, zur temporären Glaubensschwäche, zum Kleinglauben, zur Neugierde oder gar zum Ausdruck der Suche nach Christus, um das Ansehen des Apostels zu >retten<. ${ }^{54}$

Interessanterweise markiert auch hier die Reformation einen Bruch mit der exegetischen Tradition. Zum einen wird die Kritik am Verhalten des Thomas nun teilweise deutlich massiver, und zum anderen wird nun erstmals wieder stärker die Frage aufgeworfen, ob Thomas wirklich die Wundmale Jesu berührt hat. Johannes Bugenhagen $^{55}$ und andere Lutheraner »bestreiten [...], dass Thomas Jesus wirklich berührt habe« oder legen dieser Berührung nur noch wenig Bedeutung bei. ${ }^{56}$ Calvin, der die Thomasepisode in seinem Johanneskommentar durchaus im Sinne der älteren Tradition als Befestigung des Glaubens und darüber hinaus als Beleg der Fürsorge Christi für den Glauben des Thomas und aller Christen interpretiert, stellt gleichzeitig die Starrsinnigkeit des Thomas als warnendes Bei-spiel scharf heraus. Sein Verhalten sei Selbstüberhebung, ja »Beleidigung Christi. $\aleph^{57}$ Wolfgang Musculus vergleicht gar die Bevorzugung des Zeugnisses der Sinne gegen-

\footnotetext{
${ }^{53}$ Gregor d. Grosse, Homiliae in Evv. 26,7, (aus: M. Fiedrowicz, Fontes Christiani II 28,2, Freiburg 1998, 487). So auch ein Fragment des Ammonius (aus: J. Reuss [Hg.], Johanneskommentare aus der griechischen Kirche, Berlin 1966, 354 [zit. in: Ancient Christian Commentary on Scripture IVb, John 11-21, Downers Grove 2007, 368]): "It fit God's purpose that Thomas did not believe, so that we all might know through him that the body that had been crucified had been raised. "Weitere Zeugnisse ebd. ${ }^{54}$ Dazu zahlreiche Belege bei Most, Der Finger in der Wunde, 188.

${ }^{55} \mathrm{G}$. Buchwald, Ungedruckte Predigten Johann Bugenhagens aus den Jahren 1524 bis 1529, Quellen und Darstellungen aus der Geschichte des Reformationsjahrhunderts 13, Leipzig 1910, 324.

${ }^{56}$ Most, Der Finger in der Wunde, 190.

57 Calvin, Johanneskommentar, zu Joh 27, in: Johannes Calvins Auslegung der Heiligen Schrift in deutscher Übersetzung, Bd. 10: Das Evangelium des Johannes, Neukirchen $1941,522$.
} 
über dem heiligen Wort Gottes mit der Entscheidung für Satan statt für Gott. ${ }^{58}$ Hinter dieser negativeren Bewertung des Thomas mag zum einen die Tatsache stehen, dass die ausserbiblischen Legenden über Thomas in der reformatorischen Exegese keine Bedeutung mehr hatten, zum anderen steht die Lehre von der Begründung des Glaubens durch Christus bzw. das Wort allein dem Interesse am Wunder bzw. an der Verifikation durch die menschlichen Sinne entgegen. Somit konnte dem Handeln des Thomas, seiner 'Fingerprober keine konstitutive Bedeutung mehr beigemessen werden. Schliesslich waren für die Reformatoren auch die zuvor oft dominanten dogmatischen Detailfragen nach der Natur des Leibes des Auferstandenen als unfruchtbare Scholastik irrelevant geworden, so dass die seit den antignostischen Autoren bestimmende Sichtweise auf die Thomasperikope als eines Beweises der leiblichen Auferstehung zugunsten der Konzentration auf die Frage von Glaube und Unglaube aufgegeben werden konnte.

\section{Thomas, der Zweifler, und der Glaube der Leserinnen und Leser des Evangeliums}

Kommen wir von hier aus noch einmal zur Auslegung in der Gegenwart zurück. Der eklektische Durchgang durch Auslegungen und bildnerische Umsetzungen der Perikope macht hellhörig für die Bewertung der Thomas-Gestalt und des in dieser Perikope ausgesprochenen Wunsches nach Autopsie oder auch persönlicher Erfahrung im Gegensatz zu der Forderung nach einer schlichten Gläubigkeit gegenüber dem Zeugnis anderer oder der Überlieferung. Welche Bedeutung kann das Sehen im Bezug auf den Glauben haben? Und welchen Sinn die sleibliche`, sinnliche Wahrnehmung? Bietet die Thomas-Episode etwa eine biblische $>$ Rechtfertigung des Zweifels?? Kann Thomas gar als Leitfigur des sogenannten smodernen Menschen gelten, der - wie oft gesagt wird - auch nur glauben kann und will, was er sieht? Als Repräsentant des der Tradition und dem blossen Hörensagen gegenüber skeptischen Zeitgenossen? Steht er paradigmatisch für die Zielgruppe von sThomasmessen und anderen kirchlichen Angeboten für Fernstehende? Lässt sich diese Wirkungsspur vor dem biblischen Text rechtfertigen? Und wie lassen sich die anderen Spuren der Wirkungsgeschichte an das

${ }^{58}$ S. dazu Most, Der Finger in der Wunde, 190. 
Verständnis des Textes zurückbinden? Daher ist abschliessend noch einmal nach dem Text in Joh 20,24-29 zu fragen.

Dabei unterscheidet sich der Rahmen des heutigen exegetischen Fragens signifikant von allen älteren Ansätzen. Der unmittelbare Zugang zu einem historischen Geschehen hinter dem johanneischen Text, wie er früheren Interpreten offen stand, ist uns verwehrt. Das vierte Evangelium ist nicht einfach Abbild historischer Begebenheiten, und eine Lektüre, die aus ihm weithin einen tatsachengetreuen Bericht der Geschichte des irdischen Jesus erheben will, scheitert nicht nur an den Differenzen mit den synoptischen Evangelien und den z.T. massiven historischen „Unmöglichkeiten innerhalb des johanneischen Berichts, sondern in erster Linie an der höchst selektiven und deutungsorientierten Darstellungsweise des johanneischen Textes. ${ }^{59}$ Das vierte Evangelium kann aber auch nicht einfach als Darlegung der theologischen Wahrheit gelesen werden, weil die in ihm zutage tretende theologische Sichtweise zunächst als Ausdruck der Sichtweise seines menschlichen Autors oder des dahinter stehenden Zeugenkreises zu sehen und in die theologischen Diskurse der frühchristlichen Zeit einzuordnen ist. So ist die Thomasepisode zunächst ein Zeugnis des vierten Evangelisten, das im Rahmen seiner narrativen Strategie und seiner theologischen Anliegen zu lesen ist. Es ist mit aller Wahrscheinlichkeit kein Augenzeugenbericht, sondern autorisiert durch den sachlichen Anspruch, der sich im Zeugnis des `Lieblingsjüngers ‘ bekundet (Joh $21,24 f$.) und der sich letztlich pneumatologisch auf das serinnernde und zum wahren Verstehen der Geschichte Jesu führende Wirken des nachösterlichen Geistes zurückführt.

Damit ist auch die Figur des Thomas, wie sie (erst) im vierten Evangelium Konturen bekommt, nicht mehr als eine historische Gestalt zugänglich, deren Charakter und Entwicklung - vom Unglauben zum Glauben, oder von einem vormaligen Glauben durch eine Phase des Zweifels zur Erneuerung des Glaubens - wir noch nachzeichnen könnten. Es ist vielmehr eine literarische Figur, anhand derer der johanneische Erzähler den Lesern - und in zweiter oder dritter Linie auch uns - den Weg vom Unglauben zum österlichen Glauben zu vermitteln versucht. Gegenstand des Interesses ist

\footnotetext{
${ }^{59}$ Die apologetische Argumentation, wie sie in konservativ-evangelikalen Kreisen immer wieder aufgenommen wird, verkennt - aus einem ernst zu nehmenden Anliegen heraus - wesentliche Aspekte des Textes; s. zuletzt etwa C.L. Blomberg, The Historical Reliability of the Fourth Gospel. Issues and Commentary, Downers Grove 2001, sowie einzelne Beiträge aus dem Sammelband P.N. Anderson u.a. (Hg.), John, Jesus and History,Vol. 2: Aspects of Historicity in the Fourth Gospel, Atlanta 2009
} 
damit weniger der Zweifel des Thomas als der mögliche Zweifel der johanneischen Leserinnen und Leser bzw. die für diese bestehende (prinzipielle) Schwierigkeit, die Osterbotschaft in nachösterlicher Zeit zu fassen. Erst aufgrund dieser literarischen Wahrnehmung ist dann auch aus dem johanneischen Zeugnis ein sachlicher Ertrag im Blick auf das theologische Verhältnis von Kreuz und Auferstehung oder auch für das Verständnis von Hören, Sehen und Glauben zu entnehmen.

Literarisch ist die Thomasepisode im Rahmen der johanneischen Ostererzählungen von Joh 20 zu betrachten, als deren Klimax sie kurz vor dem ersten Buchschluss (Joh 20,30f.) eingefügt ist - nach den Szenen der Entdeckung des leeren Grabes durch Petrus und den `Lieblingsjünger`, der Offenbarung Jesu vor Maria Magdalena und der Erscheinung im Jüngerkreis. Nach der dort erfolgten Geistmitteilung und Sendung der Jünger in ihre nachösterliche Wirksamkeit erscheint die nochmalige Fokussierung auf einen einzelnen Jünger (mit der Angabe, dieser sei bei der ersten Erscheinung nicht dabei gewesen), als ein noch einmal retardierendes Element, dessen Funktion literarisch zu bestimmen ist. Dass diese `Erweiterung` der Erzählung von der Erscheinung Jesu im Jüngerkreis von Gewicht ist, geht nicht zuletzt daraus hervor, dass der Evangelist damit die Inkonsistenz in Kauf nimmt, dass Thomas - wenn er in der vorigen Szene nicht zugegen ist, nicht als Adressat der Sendung und Geistmitteilung von V. 22 f. erscheint. ${ }^{60}$ Seine narrative >Ausgliederung $<$ hat ihren Preis, der sachlich vom Evangelisten kaum intendiert sein dürfte - freilich von späteren Auslegern gelegentlich irritierend wahrgenommen wurde. Die Frage stellt sich daher noch verschärft, worauf es dem Evangelisten hier ankommt.

Intertextuell ist festzuhalten, dass die Thomasepisode keine Parallelen in anderen Evangelien besitzt. Während die zuvor erzählte Erscheinung Jesu im Jüngerkreis Joh 20,19-23 enge Bezüge zu dem Bericht in Lk 24,36-49 besitzt und sich auf dem Hintergrund dieses Textes in ihrem Profil erschliesst, ${ }^{61}$ ist die Erscheinung Joh 20,2429 in ihrer Grundstruktur parallel zu 20,19-23 gestaltet und bietet darüber hinaus spezifische Rückbezüge auf andere johanneische Passagen. Hierzu zählen zunächst die Erwähnungen der Figur des

\footnotetext{
${ }^{60}$ Nichts deutet in V. 19-23 darauf hin, dass der Jüngerkreis (gleich welchen Umfangs) nicht vollständig gewesen sei. Das Fehlen des Thomas klappt auffällig nach.

${ }^{61}$ Dazu J. Frey, "Ich habe den Herrn gesehen" (Joh 20,28). Entstehung, Inhalt und Vermittlung des Osterglaubens nach Johannes 20, in: A. Dettwiler u.a. (Hg.), Studien zu Matthäus und Johannes / FS J. Zumstein, AThant 97, Zürich 2009, 267-284, hier $278-280$.
} 
Thomas (11,16; 14,5), dann die Szene des Lanzenstichs (Joh 19,34) und - in der Formulierung der `Glaubensbedingung` des Thomas der Tadel Jesu an einem blossen >Wunderglauben ' in Joh 4,48. ${ }^{62}$ Insofern legt sich die Folgerung nahe, dass es sich bei der Perikope um eine literarische Schöpfung des Evangelisten handelt - eine shistorisierender Lektüre ist unangebracht, und mit ihr sind auch alle an diese Dimension anschliessenden Fragen (z.B. nach dem Charakter des Thomas, der Natur des Auferstehungsleibes, der Art der Kreuzeswunden etc.) verfehlt.

In der Sequenz der Szenen von Joh 20 wird häufig eine gewisse Stufenfolge wahrgenommen: Wie sich die Manifestation der Leiblichkeit des Auferstandenen von Szene zu Szene steigert, von der blossen Wahrnehmung der zusammengelegten Leichentücher im leeren Grab bis hin zum Aufweis der Hände und der Seite und der Nägelmale in Jesu Wunden, so scheint die Glaubensgewissheit von Szene zu Szene abzunehmen: Vom Lieblingsjünger, der glaubt, ohne zu sehen, bis hin zu Thomas, der nicht glauben will, ohne (nicht nur zu sehen, sondern gar) den Auferstandenen zu betasten. ${ }^{63}$

Freilich verführt eine solche Sichtweise dazu, Thomas in die radikale Gegenposition zu jenem idealen Jünger zu rücken, und die Seligpreisung derer, die (wie der Lieblingsjünger) "nicht sehen und doch glauben", erscheint dann doch allzu leicht als ein Tadel an dem von Thomas geäusserten Begehren. Diese Tendenz, die z.B. im Kommentar Rudolf Bultmanns noch auf die »durchschnittliche Haltung der Menschen« hin verallgemeinert und letztlich überhaupt gegen den Wert der Ostergeschichten ins Feld geführt wird, ${ }^{64}$ ist insofern problematisch, als Jesus nach Joh 20,27 doch gerade die Erfullung seines Begehrens anbietet und ihm zumindest die Schau seinerWundmale gewährt, wenn auch eine tatsächliche $>$ Fingerprobe dann nicht mehr erzählt ist. Eine radikale Entgegensetzung von

\footnotetext{
62 Natürlich begehrt Thomas keine ,Zeichen und Wunder im Sinne von Joh 4,48. Seine Aussage repräsentiert aber gleichfalls eine irdische Sichtweise, wie sie dem dort kritisierten Wunderglauben zu eigen ist. Der Bezug auf Joh 4,46-54 ist auch dahingehend interessant, dass Thomas wie der königliche Beamte durch den Ausdruck des wunderbaren Wissens Jesu (Joh 4,50) - d.h. durch sein Wort - überwunden und zum Glauben gebracht wird. Im Übrigen ist ein Bezug dadurch noch einmal verstärkt,

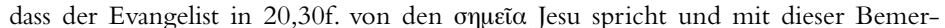
kung vermutlich nicht nur auf die im Verlauf des öffentlichen Wirkens Jesu erzählten Wunder rekurriert, sondern auch die Ostererzählungen, zumindest deren letzte Szene, einschliessen könnte (so z.B.U. Schnelle, Das Evangelium nach Johannes, ThHK 4, Leipzig ${ }^{3} 2004,331$ ).

${ }^{63}$ So Schnelle, Evangelium, 322. Zur kritischen Modifikation s. ebd., 282f.

${ }^{64}$ R. Bultmann, Das Evangelium des Johannes, KEK 2, Göttingen ${ }^{21} 1986,539 f$.
} 
Sehen und Glauben entspricht zwar einer Tradition protestantischer Worttheologie, die bei Bultmann durch die >Entmythologisierung des Wunders und die massive Infragestellung des Werts der Ostererzählungen noch gesteigert hervortritt. Sie wäre aber zu einseitig und verkennt, wie in der Forschung nach Bultmann wieder deutlicher herausgearbeitet wurde, dass den als `Zeichen charakterisierten Wundererzählungen ${ }^{65}$ und damit der visuellen Dimension eine wesentlich positivere Rolle im Prozess der Entstehung des Glaubens zugeschrieben wird. ${ }^{66}$ Selbst der $>$ Lieblingsjünger` sieht nach Joh 20,8 zwar nicht den Auferstandenen, aber doch die Leichentücher und das Schweisstuch. Er sieht die Zeichen im Grab und glaubt angesichts dieser Wahrnehmung. ${ }^{67}$ Er weiss - im Unterschied zu Petrus, der noch unverständig bleibt - die Zeichen im Grab richtig zu deuten. D.h., der Glaube kommt in johanneischer Sicht nicht allein aus dem Hören, ${ }^{68}$ sondern auch aus dem Sehen der Zeichen bzw. der Werke Jesu. Daneben sind auch andere sinnliche Wahrnehmungen wie das Schmecken (Joh 2,9), Riechen (Joh 12,3; vgl. 11,39) und Betasten (Joh 20,27; vgl. 1 Joh 1,1) an mehreren Stellen auffällig in dieses Ensemble der ssinnlichen Wahrnehmungen einbezogen. ${ }^{69}$ Insofern lässt sich zwischen dem Lieblingsjünger und Thomas kein Gegensatz in dem Sinne konstruieren, dass der eine einen rein geistigen, von sinnlicher Wahrnehmung unabhängigen Glauben hätte, während der andere an die sinnliche Wahrnehmung, das Sehen oder gar Betasten gebunden sei.

Die narrative Struktur der Thomasepisode lässt sich insbesondere von zwei Beobachtungen her verstehen. ${ }^{70}$ Zum einen ist die Begegnung Jesu mit Thomas in klarer Parallelität zur vorher erzählten Begegnung mit dem Jüngerkreis angelegt. Wie Thomas von seinen

\footnotetext{
${ }^{65}$ Dass die Erzählung selbst (und damit der `Deutung beinhaltende Text) das `Zeichen ist, das die Rezipienten richtig verstehen sollen, hat C. Welck, Erzählte Zeichen. Die Wundergeschichten des Johannesevangeliums literarisch untersucht mit einem Ausblick auf Joh 21, WUNT 2/69, Tübingen 1994, aufgewiesen.

${ }^{66} \mathrm{~S}$. dazu grundlegend F. Hahn, Sehen und Glauben im Johannesevangelium, in: Ders., Studien zum Neuen Testament I (hg. von J. Frey/J. Schlegel), WUNT 191, Tübingen 2006, 521-537.

${ }^{67}$ Schon diese Wahrnehmung impliziert die Leiblichkeit der Auferweckung Jesu.

${ }^{68}$ So in lutherischer Tradition noch C. Koester, Hearing, Seeing and Believing in the Gospel of John, Biblica 70 (1989), 327-348.

${ }^{69}$ Dazu jetzt programmatisch R. Hirsch-Luipold, Gott wahrnehmen, Habil.-Schrift Göttingen 2010, erscheint in WUNT (in Vorbereitung), mit einer luciden Interpretation der Perikopen aus Joh 2; Joh 11-12 und Joh 20.

${ }^{70}$ Zusammengestellt bei M. Lang, Johannes und die Synoptiker. Eine redaktionsgeschichtliche Analyse von Joh 18-20 vor dem markinischen und lukanischen Hintergrund, FRLANT 182, Göttingen 1999, $287 f$.
} 
Mitjüngern bezeugt wird: "Wir haben den Herrn gesehen« (V.25), so war es auch vorher den Jüngern von Maria Magdalena gesagt worden (V.18): »Ich habe den Herrn gesehen. "Wie Thomas, so hatten auch jene diesem Zeugnis zunächst nicht geglaubt und sich "aus Furcht vor den Juden" eingeschlossen (V. 19), und bemerkenswerterweise wird eben der Sachverhalt, dass "die Türen verschlossen waren«, auch für die Zusammenkunft acht Tage später wiederholt (V. 26) so dass sich die Frage stellt, ob der Glaube der anderen Jünger die erwähnte Furcht nicht beseitigt hat. Mehr noch:Von "glauben" ist in V. 19-23 explizit gar nicht die Rede, lediglich von Freude (V. 20), und das Sendungswort und die Geistmitteilung (V. 22f.) sowie das nachmalige Zeugnis (V. 25) lassen nur implizit vermuten, dass die anderen Jünger nun in gewisser Weise zu österlich Glaubenden geworden sind. Schliesslich ist festzuhalten, dass auch die anderen Jünger keineswegs durch Jesu Wort allein zu diesem >Glauben` gekommen sind, sondern durch den Zusammenklang der Anrede durch Jesus (mit dem Friedensgruss) und der visuellen Identifikation, indem Jesus ihnen seine Hände und seine Seite zeigt. Offenbar führt auch bei ihnen erst dieses Element sinnlicher Wahrnehmung zur Erkenntnis der Identität des Begegnenden mit »dem Herrn. "Das Begehren des Thomas geht nur darin über das den anderen Widerfahrene hinaus, dass er durch die Nennung der Nägel, der Folterwerkzeuge, sein Begehren noch drastischer formuliert. Doch ist der Graben zwischen Thomas und den anderen Jüngern letztlich nicht so gross, es scheint eher, als wäre in V. 24-29 ein Problem gleichsam mit der Lupe bearbeitet, das auch schon in der vorausgehenden Szene präsent ist: das Problem, dass Glaube an Christus nicht allein auf Zeugnis anderer hin entstehen kann, sondern eine eigene Begegnung voraussetzt, zumal wenn die Glaubenden dann ihrerseits wieder als Zeugen in die Weitergabe der Botschaft eintreten sollen. Diese Begegnung wird in V. 19-23 den anderen Jüngern - leiblich-visuell - gewährt, und das Problem, dass das blosse Zeugnis anderer nicht ausreicht, wird in der Thomasepisode noch einmal in besonderer Nachdrücklichkeit und Drastik - und im Mund einer Einzelperson - formuliert.

Dass es dem Evangelisten eben auf diese Struktur der Glaubensvermittlung ankommt, legt eine zweite Beobachtung nahe. Die narrative Struktur der Thomasperikope ist erstaunlich parallel der Struktur der in Joh 1,45-49 erzählten Begegnung Jesu mit Nathanael: Auch dort wird Nathanael von einem anderen Zeugen, nämlich Philippus, das Zeugnis des Glaubens übermittelt ("Wir haben den gefunden«), das Nathanael zunächst mit einem skeptischen Einwand zurückweist $(1,46 \mathrm{a})$. Auch dort kommt es dann zur Begegnung Jesu 
mit dem Skeptiker, in der Jesus diesen anredet und dadurch seine Skepsis überwindet (Joh 1,47f.), so dass dieser am Ende ein veritables Bekenntnis spricht (Joh 1,49), das schliesslich noch von Jesus kommentiert wird (Joh 1,50:»Weil ich dir gesagt habe [...] glaubst du..$^{71}$ Die Parallele zwischen beiden Passagen ist auffällig, freilich zeigt sich in der Nathanael-Episode eine narrative Struktur, die in ihren Grundzügen im Eingang des Johannesevangeliums häufiger wiederkehrt und in dieser Wiederholung die Leser in ein bestimmtes Verständnis des Glaubens einführt: Der Glaube der ersten Jünger entsteht durchgehend (mit einer Ausnahme ${ }^{72}$ ) auf das Zeugnis eines anderen hin in Verbindung mit einer persönlichen Begegnung mit Jesus, d.h. durch das Zusammentreten von Zeugenwort und persönlicher Begegnung, von Hören und 'Sehen Jünger auf das Zeugnis des Täufers hin zu Jesus, sie »kommen und sehen" (Joh 1,39) und bleiben bei ihm. Petrus und Nathanael hören durch andere von Jesus und werden von ihm selbst angesprochen und so zu Jüngern gemacht (Joh 1,42.48-51), und auch die zum Glauben gelangten Samaritaner betonen am Ende, dass sie nicht allein aufgrund des Zeugnisses der Frau, sondern aufgrund der eigenen Begegnung glauben (Joh 4,42). In der Ausgestaltung der Jüngerberufung weicht die johanneische Darstellung bekanntlich signifikant von der synoptischen ab, und man kann vermuten, dass der Evangelist, indem er nicht den schroffen Nachfolgeruf Jesu, sondern eine komplexere Kette des Zeugnisses der Zeugen als Modell der Einführung in die Jüngerschaft verwendet, die Verhältnisse zu seiner Zeit, d.h. in der nachösterlichen Zeit, vor Augen hat, in der Glaube überhaupt nur noch auf das (mündliche oder gar buchgewordene) Zeugnis von Zeugen hin möglich ist. Dass er dennoch narrativ in Joh 1,35-51 und explizit in Joh 4,42 an der Bedeutung einer personalen Begegnung mit Christus festhält, die ja den nachösterlichen Lesern in dieser Unmittelbarkeit nicht mehr möglich ist, bietet für die Zeit der Abfassung des Evangeliums ein Problem, denn eine unmittelbare personale Begegnung mit Jesus ist für die nachösterlich Lebenden nicht mehr möglich. Andererseits ist gerade die >Normalsituation in nachösterlicher Zeit signifikant von der Situation der ersten Osterzeugen unterschieden.

An der Schwelle zur nachösterlichen Zeit, in der Darstellung der österlichen Begegnungen, muss dieses Problem bearbeitet werden, und dies dürfte der Grund sein, warum ein individueller Jünger noch

${ }_{71}$ Lang, Johannes und die Synoptiker, 287f.

${ }^{72}$ Joh 1,43: Philippus wird direkt von Jesus gerufen - im Stil der synoptischen Berufungen $\mathrm{Mk}$ 1,16-20 parr. 
einmal in besonderer Deutlichkeit die Frage der Aneignung des Glaubens bzw. der Möglichkeit der persönlichen Vergewisserung thematisiert. Hinsichtlich der Frage der Leiblichkeit des Auferstandenen bringt Joh 20,24-29 keine weitere Steigerung gegenüber dem bereits in Joh 20,20 gebotenen Eindruck der leiblichen Gestalt des Gekreuzigten, wobei dort »seine Hände und seine Seite« ebenso, wenngleich weniger drastisch als der Hinweis auf die Nägelmale in Joh 20,25, auf die stigmata des Gekreuzigten verweisen. Diese fungieren erzählerisch als Moment der Identifikation. Theologisch noch gewichtiger verweisen sie darauf, dass Jesu Auferstehung nicht einfach ein Rückgängigmachen seines Todes bedeutet, sondern dass der Auferstandene stets und bleibend der Gekreuzigte ist.

Freilich scheint der Aspekt der Sicherung der materialen Leiblichkeit der Auferstehung nicht das Hauptanliegen des Textes zu sein. Es geht auch nicht nur um die Sicherstellung der Identität des Auferstandenen mit dem Gekreuzigten, denn auch diese ist bereits in den beiden vorherigen Szenen der Begegnung Jesu mit Maria und des Erscheinens im Jüngerkreis thematisiert und in Joh 20,20b eigentlich geklärt.Vielmehr weisen der Schluss der Perikope, die Aufforderung Jesu an Thomas zu glauben, dessen Bekenntnis zu Jesus als "Herr» und "Gott" und v.a. der kommentierende Makarismus Joh 20,29 darauf hin, dass die Frage des Glaubens und der Glaubensvermittlung in nachösterlicher Zeit das eigentliche, hier bearbeitete Problem bilden. Das virulente Problem, das den Evangelisten zur Anfügung der Thomas-Perikope nötigte, ist mithin nicht einfach die Frage: »Ist der Gekreuzigte wirklich und leiblich auferstanden?« Diese Frage wäre auch schon mit den vorausgehenden drei Szenen hinreichend beantwortet. Weiterhin bedrängend ist vielmehr die Frage, wie die Aneignung des Glaubens möglich sein soll in einer Zeit, in der es zwar das Zeugnis der Zeugen gibt, letztendlich das Buch, das geschrieben ist, "damit ihr glaubt« (Joh 20,30f.), aber in der die Rezipienten dieses Zeugnisses doch nicht mehr im Sinne einer unmittelbaren Begegnung mit Jesus »sehen" können. Wie kann Glaube dann noch vermittelt werden, wenn er doch eigentlich auf einer persönlichen Begegnung mit Jesus basiert, dieser aber aufgrund seines Todes bzw. nach Ostern unsichtbar, entzogen und scheinbar abwesend ist? Das Ansinnen des Thomas erweist sich somit als »das Ansinnen aller Zu-spät-Gekommenen «. ${ }^{73}$ Der Makarismus zielt deutlich auf diese Zukunft, er ist nicht als ein Tadel an Thomas formuliert, dessen Sehen- und Begreifenwollen ihn dann als `Nicht-Seligen`, als Schwergläubigen oder gar als re-

\footnotetext{
${ }^{73}$ So Hirsch-Luipold, Gott wahrnehmen, 289
} 
nitenten Zweifler zu kategorisieren erlaubte. Er ist vielmehr eine Heilszusage an die Leserinnen und Leser des Evangeliums, die trotz ihrer andersartigen Situation glauben sollen und können und denen darin das Heil zugesprochen wird.

Warum dies so ist, erschliesst sich letztlich auf dem Hintergrund der johanneischen Abschiedsreden bzw. der Pneumatologie des vierten Evangeliums. Im Durcharbeiten der Abschiedssituation bzw. der für die Adressatengemeinde faktischen Erfahrung der Abwesenheit Jesu (Joh 14,18), seiner Unsichtbarkeit (Joh 16,10; 16,16ff.) und - gegenüber der >Welt « wie gegenüber dem Zweifel des eigenen Herzens Unaufweisbarkeit (vgl. Joh 16,20), ist es der Geist-Paraklet, der an Jesu Stelle bei den Jüngern sein soll (Joh 14,16f), der also Jesu Präsenz über Kreuz und Auferstehung hinaus >verlängert bzw. in einer neuen Qualität möglich macht. Der Geist wirkt dabei nicht nur zum besseren und vertieften Verständnis der Worte und der Geschichte (Joh 14,25f.), sondern auch zur Vergewisserung in der Wahrheit des Glaubens und damit zu einer innerlichen, sgeistigen mit Christus und dem Vater, die im Johannesevangelium durch die Aussagen der Einwohnung (Joh 14,23) und der des gegenseitigen In-Seins (»ihr in mir, ich in euch«) zur Sprache gebracht wird.

Die von Thomas berichtete Christusbegegnung gehört natürlich noch nicht $\mathrm{zu}$ dieser Kategorie. Sie ist vielmehr eine jener Begegnungen der österlichen Zeugen, also derer, die gemäss der johanneischen Erzählung noch mit ihren physischen Augen gesehen haben und mit ihren Händen zumindest hätten betasten können. Dabei ist der Fokus textlich gerade nicht auf der Nachprüfung durch Thomas (die nicht erzählt wird), sondern auf der Initiative Jesu, der eigens wegen diesem einen Jünger noch einmal erscheint, der Thomas seinen nur vor den Mitjüngern geäusserten Zweifel entgegenhält, ihm die >Fingerprober tatsächlich anbietet und ihn schliesslich zum Glauben (be)ruft. Freilich erfolgt die Begegnung Christi mit Thomas sozusagen rauf der Grenze $<{ }^{74}$ im Übergang von einem Verständnis der Nachfolge, das an der physischen Dimension des Leibes Jesu und seiner Gegenwart festhalten will, zu einem Verständnis, das trotz seiner physischen Absenz seine neue Präsenz im Geist erfasst. Die physische Realität der Wahrnehmung ist hier - wie auch bei Maria und bei den anderen Jüngern - fraglos festge-

${ }^{74}$ M. de Jonge, Signs and Works in the Fourth Gospel, in: T. Baarda u.a. (Hg.) Miscellanea Neotestamentica II, NT.Sup 48, Leiden 1978, 119, nennt Thomas "a borderline case«, weil er der letzte ist, der Zeichen sieht und der erste, der auf das Wort Jesu hin zu einem klaren Bekenntnis des Glaubens an Christus kommt. 
halten, und in der Zeugenschaft über diese Dinge sind und bleiben die Osterzeugen von allen Späteren unterschieden.

Freilich wird man hinsichtlich der Frage einer tatsächlichen Berührung des Leibes Jesu dann beim johanneischen Text bleiben und auf eine Konjektur verzichten müssen. Eine Berührung wird gerade nicht erzählt, und sie ist in Anbetracht der Anrede durch Jesus offenbar auch nicht mehr erforderlich. Thomas nimmt die zuvor begehrte Fingerprobe nicht mehr vor, sie wäre ein Festhalten an einem bisherigen Verständnis der Nachfolge des irdischen, physisch präsenten Jesus. Vielmehr bekennt er sich auf das Wort hin, das ihn in seinen tiefsten Wünschen erkennt und zugleich zum Glauben ruft, in unüberbietbarer Weise zu Jesus als zu seinem `Herrn und Gott<, er "spricht das Hochbekenntnis zum Verherrlichten aus, ohne dessen bleibende Wunden berührt zu haben. « $^{75} \mathrm{Im}$ `Zweifel des Thomas spricht sich somit die Spannung zwischen vorösterlicher Nachfolge und nachösterlichem Glauben aus, die Episode über den sungläubigen Thomas ist dazu gestaltet, um diesen nachösterlichen Glauben einerseits (durch das Zeugnis der Osterzeugen) mit zu begründen, andererseits aber auch die Leserinnen und Leser des johanneischen Werks in die neue Situation und in die neue Gestalt des Glaubens einzuführen, die auch ohne physisches Sehen oder physische Präsenz aufgrund des Zeugnisses der Zeugen und des vergewissernden Zeugnisses des Geistes möglich ist.

Die erzählerische Figur des Thomas ist daher nicht aufgeboten, um diese Gestalt zu desavouieren oder »durch die Kombination von falschem Draufgängertum und Unverständnis zum Prototypen des Ungläubigen [abzustempeln.] $\ll^{76}$ Noch weniger lässt sich begründen, dass diese Gestalt eingeführt wäre, um irgendwelche anderen, mit Thomas verbundenen Überlieferungen oder gar dahinter stehende frühchristliche Kreise zu diskreditieren. Vielmehr verkörpert Thomas das Problem aller Nachgeborenen, und die Art und Weise, wie Jesus seinem Ansinnen begegnet, wird somit zum Modell und zur Verheissung für diejenigen, die "nicht (mehr) sehen (können), und doch glauben."

- Dr. Jörg Frey ist Professor für Neutestamentliche Wissenschaft mit den Schwerpunkten Antikes Judentum und Hermeneutik an der Universität Zürich.

\footnotetext{
75 So L. Schenke, Johannes. Kommentar, Düsseldorf 1998, 380

${ }^{76}$ So zutreffend A. Leinhäupl-Wilke, Rettendes Wissen im Johannesevangelium. Ein Zugang über die narrativen Rahmenteile, NTA 45, Münster 2003, 286; gegen die Annahme von M.W.G. Stibbe, John as Storyteller. Narrative Criticism in the Fourth Gospel, Cambridge 1992, 206, der in Joh 20 eine Kombination der beiden früheren 'Auftritter des Thomas in Joh 11,16 und 14,5 sieht. Damit wäre die Perikope in Joh 20 deutlich unterbestimmt.
} 